\title{
A Study On Determinants Of Student's Attitude Towards Higher Education
}

\author{
V.Maheswari ${ }^{1}$,R.Haridas ${ }^{2}$ \\ ${ }^{I}$ Department of Management Studies, Karpagam University, Coimbatore, Tamil Nadu, India \\ ${ }^{2}$ Departments of Business Administration, Government Arts College for Men, Krishnagiri, Tamil Nadu, India
}

\begin{abstract}
Higher education has helped the students to realize their career goals and dreams. The present study is to determine the student attitude towards higher education programs. The purpose of survey is to explore attitudes of students and their untouched problems in colleges. This survey investigates final year under graduate students and ascertain the level of attitudes among the students in various factors. Further, the researcher investigated the 625 student's attitudes towards higher education programs at Arts and Science College in Coimbatore city. Likert attitude scale questionnaire was used. The researcher conducted interviews and obtained quantitative a well as qualitative data. The results revealed that the majority of the students determined the personal and employment attitude to continue their higher studies.
\end{abstract}

Keywords: Higher Education, Attitude, Students, Personal, Employment

\section{Introduction}

Higher education is the need of the hour. Indian education set up is distinctly different in other countries and facing crisis in the higher education segment. Team Lease Services of India Labour Report said that this has caused due to low college enrolment, the employability crisis of unskilled labour and lack of flexibility of the education sector. Despite enrolment growing from 2 lakh in 1947 to 1.6 crore in 2012, India lags behind its international counterparts. The Gross Enrolment Ratio (GER) is about $15 \%$ to $30 \%$ by the year 2020 (All India Survey on Higher Education, 2011). In 2010-11 12\% of undergraduate students enrolled in postgraduation courses and 1\% postgraduate students were doing their Ph.D., research work (Higher Education in India, 2011). Attitude is an idea charged with emotion which predisposes an action in particular social situation (Antonak, 1998). Students' attitude towards higher education is a matter of debate and discourse. Personal attitudes are the major reason unable to continue the higher education; and determine like place, family background, curiosity in the study, friends, income, occupation, accommodation, illness, parenting support etc. Similarly the students faced employment attitude such as own business, placement opportunities, find the job immediately, get highsalary etc. Students feel that seeking admission to the post-graduate course is an extension of undergraduate course.

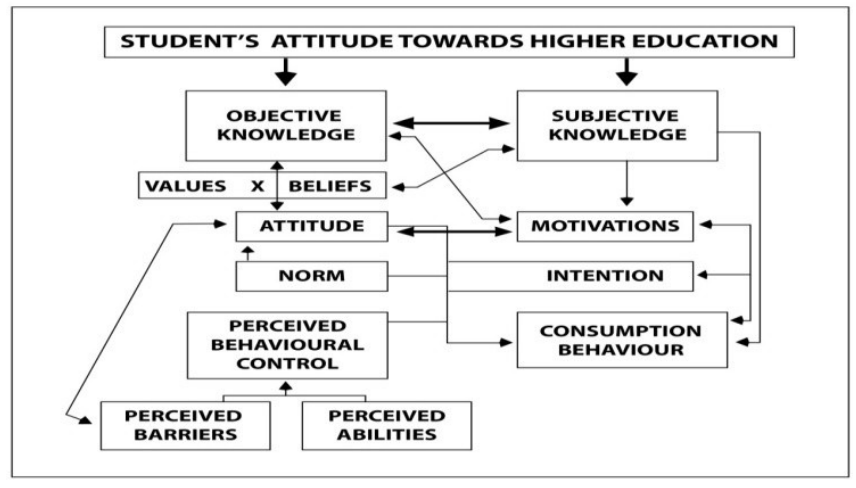

II. Review Of Literature

The research aims to study the student's attitudes and the influence of the personal and employment attitudes. Suresha and Mylarappa (2010), investigate into the career patterns and role activities of the university rural students and to ascertain the level of attitudes among the rural students. Bornholt et al (2004) highlighted salient personal and social factors in the context of changing educational aspirations and opportunities. They propose a general model of the personal and social factors to explain pathways to higher education. Silver (2003) reviews some of this literature, but suggests that the idea of one unitary culture within higher education. Archer et al (2001) researched the higher education was seen almost solely as a route to a higher salary. Many made no connection between the skills gained on a higher education course and those, which would be rewarded by this salary in jobs requiring graduate-level education. Powar (2012) argues that the co-relation between 
higher education and employment is complex in the Indian context as a number of socio-economic and technological variables are involved. These studies signifies that there is need of research in this field to find out personal and employment related to attitudes and also the effect of higher education at present. The researchers study centers around these problems leading investigation to have a purpose.

\section{OBJECTIVE OF THE STUDY:}

1. To determine the personal attitude towards students in post-graduation programs.

2. To determine the academic attitudes influencing the post graduation programs.

\subsection{Sample for the study}

\section{Methodology}

The Researchercherry picked the sample for the research. The study is mainly confined to the final year students of Arts and Science colleges in Coimbatore district. Six hundred and twenty five samples were selected, unable to continue their higher education.

\subsection{Tools Used}

To measure the student's attitude towards higher education, the investigator constructed a five-point Likert type attitude scale. The scale was constructed after identification of the component/dimensions of attitude towards the post-graduation programs through reviewing literature related to higher education. The collected data were analysed quantitatively as well as qualitatively.After the scoring procedure Regression value, square of $\mathrm{R}$, incremental value and probability were calculated to find out the distribution of the personal attitude and employment attitude. The t-test and ANOVA was utilized to find out the influence of different variables on attitude. Content analysis was done in frequency and percentage of the open-ended questions. The subjective answers of the respondents supporting their choice were qualitatively analysed.

\subsection{Research Hypothesis} education.

There will be no significant differenceingender and personal attitudes of students towards higher education.

There will be no significant difference in income and employment attitude of students towards higher

\section{Results And Discussion}

Table 1 - Results of Multiple Regression Analysis of Personal Attitude

\begin{tabular}{cccccccc}
\hline Description & Male & Female & $\mathbf{R}$ & $\mathbf{R}^{2}$ & Incremental value & p - value & $\begin{array}{c}\text { Level of } \\
\text { Significance }\end{array}$ \\
\hline $\begin{array}{c}\text { Personal } \\
\text { Attitude }\end{array}$ & 302 & 323 & 0.012 & 0.003 & 0.003 & 0.761 & 0.05 \\
\hline
\end{tabular}

Test of Hypothesis 1: Personal Attitude and Gender

Thepurpose of this study is confirmed that male and female students' attitude towards personal attitude. Female pupils have more participated than male students. There were 625 students in the sample. To measures the personal attitude of the respondents to analyze the statistical tool of multiple regressions was used.It is a functional relationship between a dependent variable and a set of independent variables. To calculate the $\mathrm{R}-$ regression value 0.012 and one independent variable is introduced at each stage to assess the incremental values in the value of R2 is 0.003 which provides the percentage of explanation on the dependent variable. The incremental value calculates the difference between the square of $\mathrm{R}$ values. The level of significance taken at $5 \%$ at the same time the result is above the significance level. The above table shows the personal factors have no significant influence ( $\mathrm{p}$ value $>0.05$ ) on the dependent variable (Gender).

Table 2 - Results of Multiple Regression Analysis of Employment Attitude

\begin{tabular}{|c|c|c|c|c|c|c|c|}
\hline Description & $\begin{array}{l}\text { Family } \\
\text { Income }\end{array}$ & No of Respondents & $\mathbf{R}$ & R2 & $\begin{array}{l}\text { Incremental } \\
\text { value }\end{array}$ & p - value & $\begin{array}{l}\text { Level of } \\
\text { Significance }\end{array}$ \\
\hline \multirow{4}{*}{ Income Level } & $\begin{array}{c}\text { Below } \\
\text { Rs. } 15,000\end{array}$ & 490 & \multirow{4}{*}{0.053} & \multirow{4}{*}{0.003} & \multirow{4}{*}{0.001} & \multirow{4}{*}{0.940} & \multirow{4}{*}{0.05} \\
\hline & $\begin{array}{c}\text { Rs. } 15,001- \\
\text { Rs. } 25,000\end{array}$ & 105 & & & & & \\
\hline & $\begin{array}{c}\text { Rs. } 25,001- \\
\text { Rs. } 50,000 \\
\end{array}$ & 16 & & & & & \\
\hline & $\begin{array}{c}\text { Above } \\
\text { Rs. } 50,001\end{array}$ & 14 & & & & & \\
\hline
\end{tabular}

Test of Hypothesis 2: Employment Attitude and Level of Income 
The second hypothesis assumes that the respondents' level of income related to the employment attitude to higher education. This study confirms that four categories to assume the level of income reported respondents to the employment attitude. There were 625 students in the sample. To measures the employment attitude of the respondents to analyze the statistical tool of multiple regressions was used.It is a functional relationship between a dependent variable and a set of independent variables. To calculate the $\mathrm{R}$ - regression value 0.053 and one independent variable is introduced at each stage to assess the incremental values in the value of R2 is 0.003 , which provide the percentage of explanation on the dependent variable. The incremental value calculates the difference between the square of $R$ values 0.001 . The incremental value is called the reverse cumulative frequency.The level of significance taken at $5 \%$ at the same time the result is above the significance level. The above table shows the employment attitude to have no significant influence ( $p$ value $>0.05)$ on the dependent variable like Below Rs.15, 000, Rs.15, 001 - Rs.25, 000, Rs.25, 001 - Rs.50, 000 and Above Rs.50, 001 of the respondents.

\section{Conclusion}

This study focused on the attitude of our youth's toward the higher education system and this finding cleared the attitude of college level students towards major two attitudes which determined the family background, friends, curriculum, college, government policies, job opportunity, business, workload, placement opportunity and promotion. The majority of the students were continuation of higher education with certain personal and employment attitude related improvements. Theiropinion revealed in this study helps to analysis various problems faced by the students to continue the higher studies. But in a traditional orientated Indian society, there is always the tendency on the part of both factors of students to be attached psychologically. In this research, today's global business, graduate need to give importance and develop their skills and knowledge through higher studies.

\section{References}

[1]. All India Survey on Higher Education (2011), Pilot Report, MHRD, Department of Higher Education, 2011 Planning, Monitoring and Statistic Bureau. pp.3

[2]. Higher Education in India (2011), Strategies and Schemes during 11th plan period (2007-12) for universities and colleges, UGC, www.ugc.ac.in. pp.1-3.

[3]. Antonak, R.F (1988) Methods to measure attitudes towards people who are disable Higher Education (ed.). Attitudes towards persons with disabilities, New York: Springer Publishing Company, pp. 106-126.

[4]. Suresha. R and B. C. Mylarappa (2010),"An investigative Attitudes of rural students in higher education”, Bangalore city.pp.3.

[5]. Bornholt, L., Gientzotis, J. And and Cooney, G. (2004) Understanding choice behaviours pathways from school to university with changing aspirations and opportunities, Social Psychology of Education, vol.7, pp. 211-228.

[6]. Silver, H (2003). Does a university have a culture? Studies in Higher Education. pp. 157-169.

[7]. Archer, L, Pratt, S D and Phillips, D (2001). Working-class men's constructions of masculinity and negotiations of (non) participation in higher education. Gender and Education. 13(4) pp. $431-449$.

[8]. Powar, K. B. (2012). Expanding domains in Indian higher education. New Delhi: Association of Indian Universities.pp.45. 